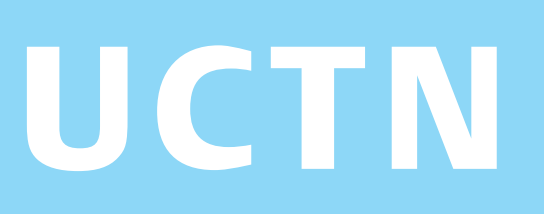

\title{
Direct percutaneous endoscopic jejunostomy tube placement using a fine needle for jejunal anchoring
}

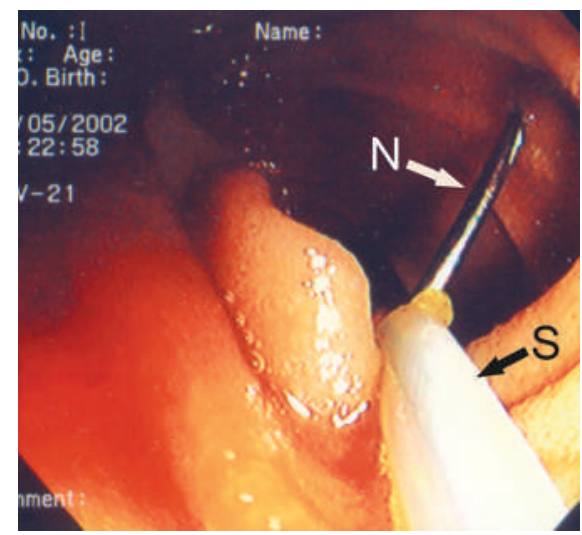

Figure 1 Insertion of a 21-gauge needle (the finder needle) into the jejunal lumen at the site of optimal transillumination. A loop snare $(\mathrm{S})$ is passed endoscopically around the finder needle $(\mathrm{N})$, resulting in attachment of the jejunum to the abdominal wall. This prevents the jejunum from sliding away during the procedure.

Percutaneous endoscopic gastrojejunostomy (PEGJ) tube placement is a technically simple procedure that is the most commonly used method of endoscopic jejunostomy. However, it only allows the placement of jejunostomy tubes with a diameter of 3-4 mm (9-12 Fr), which are prone to luminal occlusion and migration [1 - 3]. In addition, it has been reported that PEGJ tubes may not prevent aspiration resulting from frequent retrograde tube migration into the stomach and reflux of intestinal contents [1-3]. Direct percutaneous endoscopic jejunostomy (DPEJ) appears to be a better alternative to PEGJ, as it allows placement of the larger-diameter DPEJ tube in the proximal jejunum and is associated with a reduced risk of pulmonary aspiration. However, the smaller lumen, mobility, active peristalsis of the jejunal loop, and difficulty in transillumination make this procedure much more difficult than PEGJ tube placement. To overcome the above challenges, we anchored the jejunum against the abdominal wall with a 21-gauge finder needle before passing the needle and trochar (Figures 1,2 ). In addition to stabilizing the jejunum, the finder needle penetrates the soft tissue easily and is less likely to cause visceral trauma. We carried out DPEJ tube placement using this method in 21 pa-

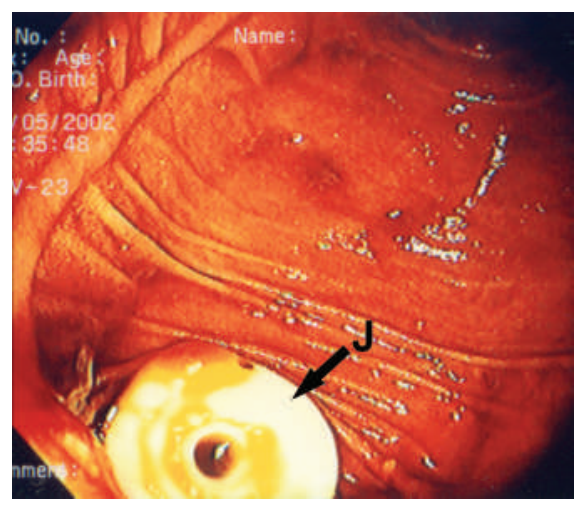

Figure 2 The jejunostomy tube (J) in the jejunal lumen. After the jejunum has been anchored with the finder needle, a long needle with a trochar is inserted parallel to the finder needle. The long needle is then snared endoscopically and the finder needle is withdrawn. A guide wire is passed through the trocar into the jejunum, snared, and pulled out of the mouth with the endoscope. The tapered end of a standard 20-Fr percutaneous endoscopic gastrostomy (PEG) tube is mounted onto the end of the guide wire and pushed through the mouth into the stomach. The guide wire is then gradually withdrawn, pulling the PEG tube (J) out through a small abdominal incision.

Table 1 Indications for direct percutaneous endoscopic jejunostomy tube placement

\begin{tabular}{lrr}
\hline & \multicolumn{2}{c}{ Patients } \\
& n & $\%$ \\
\hline Gastroesophageal regurgitation & 12 & 57 \\
\hline Pulmonary aspiration & 4 & 19 \\
\hline Gastroparesis & 3 & 14 \\
\hline Gastric resection & 2 & 10 \\
\hline Total & 21 & \\
\hline
\end{tabular}

tients for the indications listed in Table $\mathbf{1}$. The method was successful and resulted in proper placement of DPEJ tubes in 17 patients (a success rate of $81 \%$ ). In four patients, DPEJ tube placement could not be completed due to an inability to achieve adequate transillumination. No significant or major complications were associated with the procedure. Minor complications in two patients included cellulitis and cutaneous leakage of enteral contents. On the basis of this experience, it appears that DPEJ tube placement with this method is a safe and effective means of providing prolonged jejunal nutrition. Similar observations have been reported by other investigators $[4,5]$. We believe that the application of this modified technique could lead to wider acceptance of DPEJ tube placement in clinical gastroenterology.

Endoscopy_UCTN_Code_TTT_1AO_2AK

\section{A. S. Karhadkar', M. R. Rengen ${ }^{2}$, E. H.} Dubin $^{1,3}$, H. J. Schwartz 1, 3, S. K. Dutta 1, 3,4 ${ }^{1}$ Division of Gastroenterology, Dept. of Medicine, Sinai Hospital of Baltimore, Baltimore, Maryland, USA

2 Division of Gastroenterology, Hepatology and Nutrition, University of Texas Medical School, Houston, Texas, USA ${ }^{3}$ Division of Gastroenterology, Dept. of Medicine, Northwest Hospital, Baltimore, Maryland, USA

${ }^{4}$ Dept. of Medicine, University of Maryland School of Medicine, Baltimore, Maryland, USA.

\section{References}

${ }^{1}$ Wolfsen HC, Kozarek RA, Ball TJ et al. Tube dysfunction following percutaneous endoscopic gastrostomy and jejunostomy. Gastrointest Endosc 1990; 36: 261 - 263

${ }^{2}$ Henderson JM, Strodel WE, Gilinsky NH. Limitations of percutaneous endoscopic jejunostomy. JPEN J Parenter Enteral Nutr 1993; 17: 546-550

${ }^{3}$ Di Sario JA, Foutch PG, Sanowski RA. Poor results with percutaneous endoscopic jejunostomy. Gastrointest Endosc 1990; 36: 257-260

${ }^{4}$ Sharma VK, Close T, Bynoe R et al. Ultrasound-assisted direct percutaneous endoscopic jejunostomy (DPEJ) tube placement. Surg Endosc 2000; 14: 203 -204

${ }^{5}$ Varadarajulu S, Delegge MH. Use of a 19gauge injection needle as a guide for direct percutaneous endoscopic jejunostomy tube placement. Gastrointest Endosc 2003; 57: 942-945

\section{Corresponding author}

\section{S. K. Dutta, M.D.}

Division of Gastroenterology, Dept. of Medicine, Hoffberger Professional Center 2435 W. Belvedere Ave., Suite 51, Baltimore, Maryland 21215-5271, USA

Fax: +1-410-601-5757

E-mail: sudhirdutta@hotmail.com 